\title{
Occlusive Dressing Technique
}

National Cancer Institute

\section{Source}

National Cancer Institute. Occlusive Dressing Technique. NCI Thesaurus. Code C38286.

Administration of a substance by the topical route that is then covered by a dressing which occludes the area of drug application. 